\title{
A prospective study on impact of patient counselling on quality of life of patients with atopic dermatitis
}

\author{
Ranjeth R. ${ }^{1 *}$, Resmi Vijayasenan ${ }^{1}$, Amritha M. S. ${ }^{1}$, I. John Wesley ${ }^{2}$
}

${ }^{1}$ Pharm. D Intern, ${ }^{2}$ Department of Pharmacy Practice, Sree Krishna College of Pharmacy and Research Centre, Parassala, Thiruvananthapuram, Kerala, India

Received: 04 October 2020

Accepted: 06 November 2020

\section{*Correspondence:}

Dr. Ranjeth R.,

Email: ranjethrevi@gmail.com

Copyright: (c) the author(s), publisher and licensee Medip Academy. This is an open-access article distributed under the terms of the Creative Commons Attribution Non-Commercial License, which permits unrestricted non-commercial use, distribution, and reproduction in any medium, provided the original work is properly cited.

\section{ABSTRACT}

Background: Atopic dermatitis is an acute, sub-acute or chronic relapsing skin disorder characterized by intense itching, pruritus and oozing. It adversely affects the routine activities of patients for which effective treatment is to be provided along with proper counselling. The aim of the current study was to evaluate the impact of patient counselling on quality of life (QoL).

Methods: A prospective study was conducted in 108 patients recruited from the Department of Dermatology for a period of 6 months. A written informed consent was taken. Out of the 108 patients, 54 patients received tacrolimus and the remaining received corticosteroids. The collected data was analysed and presented. Data was collected by using a suitably designed proforma. Dermatology life quality index (DLQI) was used for assessing QoL. Patients were counselled regarding the disease, drugs and lifestyle modifications using patient information leaflet (PIL).

Results: The current study found that patient counselling was effective for both the groups with a $p$ value $<0.05$. The effect of disease in quality of life improved from severe to mild in both groups (prior to counselling QoL mean value of $2.93 \pm 0.61$ shifted to $1.18 \pm 0.71$ post counselling). In the tacrolimus group, QoL mean value of $2.81 \pm 0.61$ shifted to $0.98 \pm 0.71$ after counselling. In the corticosteroids group, a shift from a mean QoL value of 3.05 \pm 0.59 to a mean of $1.38 \pm 0.65$ was observed post counselling.

Conclusions: The provision of effective counselling was found to have a profound impact on improving patient's quality of life. A transition from severe effects of the disease to milder effects of the disease on quality of life was observed.

Keywords: Atopic dermatitis, DLQI, QoL

\section{INTRODUCTION}

Atopic dermatitis or atopic eczema is an itchy, chronically relapsing, inflammatory skin condition, characterized by itchy papules which become excoriated and lichenified, and typically have a flexural distribution. ${ }^{1}$ The rash is characterized by itchy papules (occasionally vesicles in infants) which become excoriated and lichenified, and typically have a flexural distribution. The eruption is often associated with other atopic conditions in the individual or other family members. ${ }^{2-4}$ Clinical features include infantile phase, childhood phase and adult phase. ${ }^{5-7}$ It typically affects the face, neck, arms, legs, groin and axillary areas. It is a childhood disease and usually starts in early infancy and about $60 \%$ and may get resolved by early adolescence but in some individuals the disease will persist. A number of population-based surveys have shown that the risk of children developing atopy is significantly higher when the mother is atopic than when the father is.$^{8-9}$ Cord blood $\operatorname{IgE}$ is high in babies whose mothers are atopic or have high $\operatorname{IgE}$, whereas pediatric atopy or raised $\operatorname{IgE}$ are associated with raised cord blood IgE. 
Atopic dermatitis may be associated with IgE mediated diseases like various allergies, asthma, allergic rhinitis, rhino conjunctivitis, etc. ${ }^{10}$ Allergens, climatic changes, aeroallergens and certain foods act as triggering factors and results in relapsing of the disease. Biopsy of developing lesions of atopic dermatitis reveals that $\mathrm{T}$ cells infiltrate the skin early in the disease process. ${ }^{11,12}$ The cellular infiltrate in atopic dermatitis is predominantly $\mathrm{T}$ lymphocytes $\left(\mathrm{CD}^{4+} \mathrm{CD}^{8+}\right.$ ratio $\left.7: 1\right)$, but eosinophils are present, albeit at lower frequencies. ${ }^{13,14}$ Most patients have dry skin, will suffer winter exacerbations, and soaps and detergents can irritate the dermatitis. ${ }^{15}$ The pharmacological treatment can be done using immunosuppressants, emollients, antihistamines etc. Non-pharmacological treatment mainly includes avoiding exposure to suspected allergens, having lukewarm short duration baths, moisturization. .,3,4,16-17 $^{-1}$

Patient counselling refers to the process of providing information, advice and assistance to help patients to use their medications appropriately. The information and advice is given by the pharmacist directly to the patient or to the patient's representatives, and may also include information about the patients' illness or recommended lifestyle changes. WHO defines quality of life as an individual's perception of their position in life in the context of the culture and value systems in which they live and in relation to their goals, expectations, standards and concerns.

Upon receiving the patients, using the PIL (patient information leaflet), general description of the disease, signs and symptoms, various lifestyle modifications and measures to avoid trigger factors like allergens (environment/food/air borne), direction for bathing, etc. were elaborated. ${ }^{1}$

The aim of the current study is to evaluate the impact of patient counselling on quality of life (QoL) of patients and to understand the extent of positivity it can reflect.

\section{METHODS}

A prospective study was conducted in patients from the Department of Dermatology in Cosmopolitan Hospital, Thiruvananthapuram with atopic dermatitis during the study period after obtaining permission for collection of data from the Institutional Human Ethical committee. The study was for a period of 6 months from December 2018 to May 2019. A written informed consent was taken from the patients diagnosed with atopic dermatitis satisfying the inclusion and exclusion criteria.

\section{Inclusion criteria}

Patients with Atopic dermatitis willing to participate in the study; Patients within 16-70 years of age with diagnosis of atopic dermatitis on the basis of Hanifin and Rajka criteria. ${ }^{18}$

\section{Exclusion criteria}

Serious skin disorders or allergies other than AD; patients on topical and systemic corticosteroids; patients taking anti-inflammatory drugs, immunosuppressants, UVA and UVB therapy, sedatives and hypnotics and other investigational drugs; and pregnancy and lactation.

All information relevant to the study was collected from case records by using a suitably designed proforma. Direct interview with patients using DLQI questionnaire was done. The forms were provided in the regional dialect (Malayalam) and the patients were requested to fill.

The dermatology life quality index (DLQI) consists of ten question questionnaire used to measure the impact of skin disease on the quality of life of patients and is designed for patients above 16 years of age and above. It was first presented at the British Association of Dermatologists annual meeting in 1993 and described in an article published in 1994 in Clinical and Experimental Dermatology. ${ }^{19,20}$ There were 10 questions covering the following topics: symptoms, embarrassment, shopping and home care, clothes, social and leisure, sport, work or study, close relationships, sex, treatment. Each question refers to the impact of the skin disease on the patient's life over the previous week. ${ }^{21}$

Patients were requested to answer the questionnaire and were counselled regarding the disease, drugs and lifestyle modifications using patient information leaflet (PIL), which was provided in English and local language (Malayalam).

The impact of patient counselling on quality of life was assessed using DLQI at the first and second visits. At the end of the study, all the parameters and scores were compared from baseline to end of study.

For data entry we had used the software Microsoft excel and all the analysis were carried out with the help of statistical software SPSS V.22 for Windows. For the improvement of scores within the group, paired t-test have been used.

\section{RESULTS}

In our study, we analysed the data collected from 108 patients with atopic dermatitis from the Department of Dermatology for a period of 6 months. 54 patients in each group, they received topical tacrolimus or topical corticosteroids. There were no drop outs. $71.3 \%(n=77)$ of patients were female and $28.7 \%(n=31)$ was male (Table 1). It indicates that majority of the patients who have atopic dermatitis are females. The disease severity ranges from mild to severe. From Table 2, most number of patients are in age slab of $21-30$ years i.e. $25 \%(n=27)$ (in tacrolimus group it was $25.9 \%$, for corticosteroid it was $24.1 \%$ respectively). The least number of patients are 
included in the age slab of 51-60 years i.e., $10.2 \%(n=11)$. By analysing these data it is clear that the atopic dermatitis is most common in young adults and the disease is less in people above 40 years. From the Table 3 , it is evident that allergy and associated disorders are risk factor for the development of atopic dermatitis. $75.9 \%$ of the atopic dermatitis patients have allergy.

Table 1: Distribution of patients based on gender.

\begin{tabular}{|lll|}
\hline Gender & Frequency & Percentage (\%) \\
\hline Male & 31 & $28.7 \%$ \\
\hline Female & 77 & $71.3 \%$ \\
\hline
\end{tabular}

Table 2: Patient distribution based on age.

\begin{tabular}{|lllllll|}
\hline $\begin{array}{l}\text { Age } \\
\text { (years) }\end{array}$ & \multicolumn{2}{c}{ Tacrolimus } & \multicolumn{2}{c|}{ Corticosteroid } & \multicolumn{2}{l|}{ Total } \\
\hline $\mathbf{1 6 - 2 0}$ & 13 & 24 & 7 & 13 & 20 & 18.5 \\
\hline $\mathbf{2 1 - 3 0}$ & 14 & 25.9 & 13 & 24.1 & 27 & 25 \\
\hline $\mathbf{3 1 - 4 0}$ & 10 & 18.5 & 12 & 22.2 & 22 & 20.4 \\
\hline $\mathbf{4 1 - 5 0}$ & 7 & 9.3 & 10 & 18.5 & 15 & 13.9 \\
\hline $\mathbf{5 1 - 6 0}$ & 5 & 9.3 & 6 & 11.1 & 11 & 10.2 \\
\hline $\mathbf{6 1 - 7 0}$ & 5 & 13 & 6 & 11.1 & 13 & 12 \\
\hline
\end{tabular}

Table 3: Patient distribution based on allergy.

\begin{tabular}{|lll|}
\hline Allergy & Frequency & Percentage (\%) \\
\hline Yes & 82 & 75.9 \\
\hline No & 26 & 24.1 \\
\hline
\end{tabular}

This study aimed to evaluate the impact of counselling on QoL of patients with atopic dermatitis. The comparison of improvement before and after counselling was assessed statistically with paired t test. A calculated $\mathrm{p}$ value less than 0.05 was considered to be statistically significant.

\section{Impact of patient counselling on quality of life (both groups)}

The impact of patient counselling on QoL was assessed using DLQI scale and was analysed by paired t test.

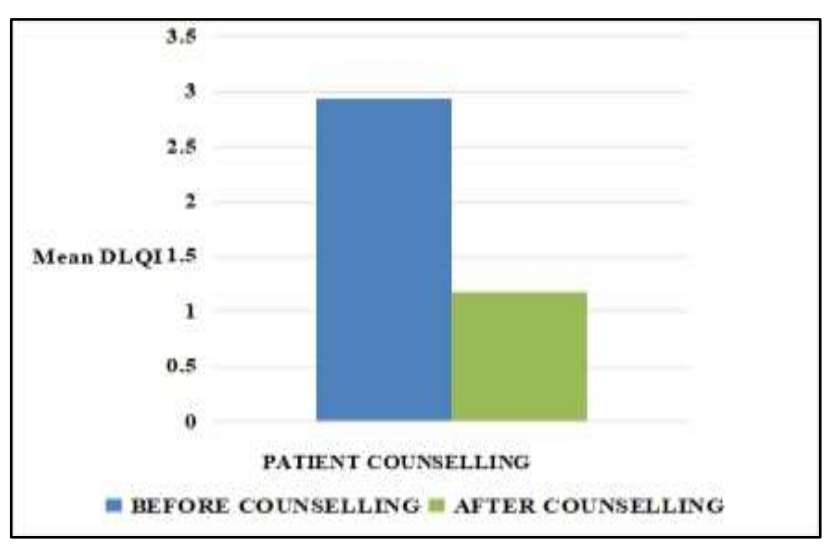

Figure 1: Diagrammatic representation of effect of counselling on QOL of AD patients in both groups.
From the Figure 1, paired t test shows significant effect on improving patient's quality of life $(\mathrm{t}=32.14$, $\mathrm{p}<0.05)$.

Table 4: Paired $t$ test for assessing the effectiveness of counselling on quality of life.

\begin{tabular}{|llll|}
\hline $\begin{array}{l}\text { Mean } \pm \text { SD } \\
\text { Before } \\
\text { counselling }\end{array}$ & $\begin{array}{l}\text { After } \\
\text { counselling }\end{array}$ & \multirow{2}{*}{32.14} & $0.000^{*}$ \\
\hline $\mathbf{2 . 9 3} \pm \mathbf{0 . 6 1}$ & $1.18 \pm 0.71$ & & \\
\hline *Significant at $\mathrm{p}<0.05$ & & \\
\hline
\end{tabular}

From the Table 4, before counselling, the QoL of patients was severely affected by the disease with a mean value of $2.93 \pm 0.61$. After counselling the effect of disease in patients QoL decreased to a mean of $1.18 \pm 0.71$ (mildly affecting). This denotes that the quality of life increased after counselling. This shift from seriously affected QoL to mildly affected QoL proved that the patient counselling had a significant effect on QoL of patients.

\section{Impact of patient counselling on quality of life (tacrolimus group)}

From the Figure 2, the paired $\mathrm{t}$ test signifies that the patient counselling have significant effect on patient QoL $(\mathrm{t}=31.82, \mathrm{p}<0.05)$.

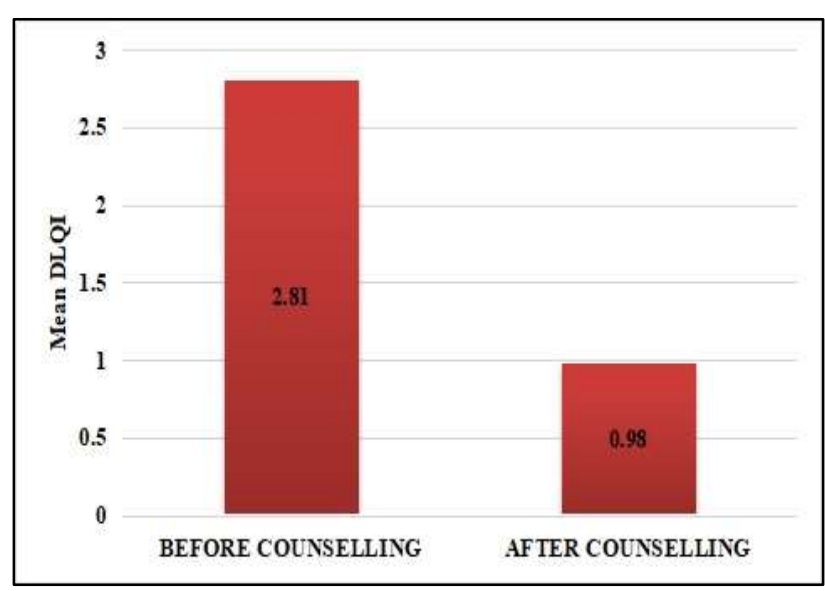

Figure 2: Diagrammatic representation of effect of counselling on QoL of patients in tacrolimus group.

Table 5: Paired $\mathbf{t}$ test for assessing effectiveness of counselling on Tacrolimus group.

\begin{tabular}{|c|c|c|c|}
\hline Parameter & Mean \pm SD & $\mathrm{T}$ value & $P$ value \\
\hline Before & $2.81 \pm 0.61$ & \multirow{2}{*}{31.82} & \multirow{2}{*}{$0.000 *$} \\
\hline After & $0.98 \pm 0.71$ & & \\
\hline
\end{tabular}

*Significant at $\mathrm{p}<0.05$

From the Table 5, before the counselling, the QoL was seriously affected by AD with a mean of $2.81 \pm 0.61$, after the counselling, the QoL improved with a mean of $0.98 \pm 0.71$. Here the QoL improved from serious to mild. 


\section{Impact of patient counselling on quality of life (corticosteroids group)}

From the Table 6 , the paired $t$ test signifies the effect of patient counselling on QoL of atopic dermatitis patients. Before the counselling, the QoL of patient was severely affected by the disease with a mean of $3.05 \pm 0.59$. After counselling, the effect of disease in patients QoL shifted from severe to mild with a mean of $1.38 \pm 0.65$. From these data, it is evident that the patient counselling had a significant effect on QoL with t value of 18.2 and $\mathrm{p}<0.05$.

Table 6: Paired $t$ test for assessing the effectiveness of counselling on QoL of patients in corticosteroids group.

\begin{tabular}{|llll|}
\hline Parameter & Mean \pm SD & T value & P value \\
\hline Before & $3.05 \pm 0.59$ & \multirow{2}{*}{18.2} & $0.000^{*}$ \\
\hline After & $1.38 \pm 0.65$ & & \\
\hline
\end{tabular}

$*$ Significant at $\mathrm{p}<0.05$

\section{DISCUSSION}

Acute dermatitis is an acute, sub-acute or chronic relapsing skin disorder characterized by intense itching, pruritus and oozing. It adversely affects the routine activities of patients for which effective treatment is to be provided along with proper counselling.

DLQI score was taken before the counselling and two weeks after the counselling. By statistically comparing the scores, effect of counselling on patients' quality of life was assessed.

In the study done by Mozaffari et al, 86 patients with AD who were referred to an immunology clinic and 98 patients ( $>4$ years old) attending a general clinic acting as controls (without any chronic or severe disease) participated in this survey. Physician filled the dermatology life quality index (DLQI) questionnaire for individuals more than 16 years via face-to-face interview. There were significant differences $(p<0.001)$. For children and adults with AD, the mean score of each question was significantly higher than in the control group $(\mathrm{p}<0.001) .^{22}$

In the cross sectional study of 132 outpatients with $\mathrm{AD}$ by Maksimovic et al, to assess the QoL, short form 36 (SF-36), dermatology life quality index (DLQI) and children's dermatology life quality index (CDLQI) were administered. Increasing disease severity was associated with greater impairment in QoL in both children and adults. $^{23}$ Our study found the influence of the stressful life events on the emotional role of AD patients. These results demonstrate that $\mathrm{AD}$ influences health-related QoL, especially in children. A study by Holm et al also explains the influence of AD on QoL of patients. ${ }^{24}$

Another study showed significant improvement in patients with less severe symptoms of atopic dermatitis. ${ }^{25}$
Further there were research papers highlighting the effectiveness of patient education programs (involving both dermatological and psychological behaviour training). ${ }^{26,27}$

A systemic review and meta-analysis of randomized controlled trials also evaluated the various types of interventions which included the cognitive-behavioral therapy, dermatological education, stress management programs and other interventions and the result revealed that psychological interventions had a significant ameliorating effect on eczema severity, itching, scratching, but a definite conclusion about the effectiveness seemed to be premature. ${ }^{28}$

Another study investigated the relationship between the severity of $\mathrm{AD}$, dermatological life quality and anxiety. Here, 32 adults suffering from AD were examined using the severity scoring of AD index (SCORAD), the DLQI and the Spielberger state-trait anxiety index (STAI). ${ }^{29}$ Twenty-two healthy controls were examined using the DLQI and STAI. Results showed that the AD group had higher anxiety and lower dermatological life quality than the control group. There was significant positive correlation between SCORAD and DLQI and between DLQI and STAI. However no correlation was found between SCORAD and STAI. It also concluded that both dermatological and psychological assessment is important in $\mathrm{AD}$.

An association between perceived stigmatization and disease severity was observed in the study by SchmidOtt et al. ${ }^{30}$

A study by Habib elaborated on stress management program implemented as an adjunct treatment in patients with and dermatitis severity assessment performed both pre and post treatment and at follow-up conducted 8 weeks after the conclusion of the program. Within the short tenure, there was reduction of all the symptoms and also provided long-term management strategies. ${ }^{31}$

All these studies indicate that atopic dermatitis can adversely affect the QoL of patients hence there is need for strongly emphasizing counselling services that can help overcome the social and the intra/inter personal stigma the patients are subjected to.

We assessed the DLQI score pre counselling and then provided counselling and provided certain modifications regarding lifestyle modification, preventive measures, etc. They were re assessed after 2 weeks during review, and the DLQI score post counselling was found to be decreased significantly which indicates that they had incorporated the measures conveyed to them during the counselling session which resulted in improvement of their QoL.

Hence, it is evident that patient counselling plays a major role in improving the QoL of patients with AD. 
Limitation includes short duration of study. In India, very few studies have been worked up on the topic of perks of counselling on patients suffering from atopic dermatitis.

Further studies have to be conducted in the future so that the effectiveness of counselling can be brought to the limelight.

\section{CONCLUSION}

Atopic dermatitis is a chronic inflammatory dermatological disorder, mainly characterized by itching, pruritus, rashes, redness, etc. It mainly arises from genegene interactions and gene-environment interactions and commonly manifests in childhood and may progress to adulthood in the presence of compromising factors. Patients need to be clearly detailed about the disease, the susceptibility of progression of disease to adulthood in the light of some pre-existing factors like allergies, asthma, etc., and also how to keep the disease on guard by providing lifestyle and dietary modifications. Hence, it is evident that patient counselling plays a major role in improving the QoL of patients with AD.

In a nutshell, the picture of current deficient literacy on the aspects of the disease among the study community has in turn brought to notice the strong emphasis that must be exercised over providing quality counselling services.

\section{ACKNOWLEDGEMENTS}

Authors would like to thank Dr. Sreelatha Devi. R., MD, Hon. Senior Consultant, Dermatology, VD and Cosmetology, Department of Dermatology, who helped us in collecting the data for this study.

Funding: No funding sources

Conflict of interest: None declared

Ethical approval: The study was approved by the Institutional Ethics Committee

\section{REFERENCES}

1. Sardana K, Khurana A, Mahajan K, Bhole A. Atopic Dermatitis. Handbook of Eczema for Dermatologists. 2nd Edition. CBS Publishers; 2019.

2. Darsow U, Lübbe J, Taieb A, Seidenari S, Wollenberg A, Calza AM, et al. Position on the diagnosis and treatment of atopic dermatitis. J Eur Acad Dermatol Venereol 2005;19:286-95.

3. Williams H. Atopic dermatitis. N Engl J Med. 2005;352:2314-24.

4. Brown S, Reynolds NJ. Atopic and non-atopic eczema. BMJ. 2006;332:584-8.

5. Aoki T, Fukuzumi T, Adachi J, Endo K, Kojima M. Re-evaluation of skin lesion distribution in atopic dermatitis. Analysis of cases 0 to 9 years of age. Acta Derm Venereol Suppl (Stockh). 1992;176:19-23.
6. Macharia WM, Anabwani GM, Owili DM. Clinical presentation of atopic dermatitis in Negroid children. Afr J Med Sci. 1993;22:414.

7. Waersted A, Hjorth N. Pityrosporum orbiculare- a pathogenetic factor in the atopic dermatitis of the face, scalp and neck. Acta Derm Venereol Suppl (Stockh). 1985;114:46-8.

8. Dold S, Wjst M, Von Mutius E, Reitmeir P, Stiepel E. Genetic risk for asthma, allergic rhinitis, and atopic dermatitis. Arch Dis Childhood. 1992;67(8):1018-22.

9. Ruiz RG, Kemeny DM, Price JF. Higher risk of infantile atopic dermatitis from- maternal atopy than from paternal atopy. Clin Exp Allerg. 1992;22:7626.

10. Ohman S. Johanason SG. Allergen-specific IgE in atopic dermatitis. Acta Derm Venereol. 1974;54:28390.

11. Grewe M, Walther S, Gyufko K, Czech W, Schöpf E, Krutmann J. Analysis of the cytokine pattern expressed in situ in inhalant allergen patch test reactions of atopic dermatitis patients. J Investigat Dermatol. 1995;105(3):407-10.

12. Thepen T, Langeveld-Wildschut EG, Bihari IC, van Wichen DF, van Reijsen FC, Mudde GC, et al. Biphasic response against aeroallergen in atopic dermatitis showing a switch from an initial $\mathrm{TH} 2$ response to a $\mathrm{TH} 1$ response in situ: an immunocytochemical study. J Allerg Clin Immunol. 1996;97(3):828-37.

13. Zachary CB, Allen MH, MacDonald DM. In situ quantification of T-lymphocytes subsets and Langerhans cells in the inflammatory infiltrate of atopic eczema. Br J Dermatol. 1985;112:149-56.

14. Lever R, Turbitt M, Sanderson A, Mackie R. Immunophenotyping of the cutaneous infiltrate and of the mononuclear cells in the peripheral blood in patients with atopic dermatitis. J Investigat Dermatol. 1987;89(1):4-7.

15. Grimalt R, Mengeaud V, Cambazard F. The steroid sparing effect of an emollient therapy in infants with atopic dermatitis: a randomized controlled study. Dermatology (Basel). 2007;214:61-7.

16. Juhlin L, Johansson SG, Bennich H, Höugman C, Thyresson N. Immunoglobulin $\mathrm{E}$ levels in atopic dermatitis, urticaria, and various dermatoses. Arch Dermatol. 1969;100:12-6.

17. Schmid P, Simon D, Simon HU, Akdis CA, Wüthrich B. Epidemiology, clinical features, and immunology of the "intrinsic" (non-IgE-mediated) type of atopic dermatitis (constitutional dermatitis). Allergy. 2001;56(9):841-9.

18. Hanifin JM, Rajka RG. Diagnostic features of atopic dermatitis. Acta Derm Venereol (Stockh). 1980;92(144):44-7.

19. Finlay AY, Khan GK. The dermatology life quality index: a simple practical measure for routine clinical use. British Association of Dermatologists Annual Meeting. Oxford. Br J Dermatol. 1993;129(42):27. 
20. Finlay AY. Khan GK. Dermatology Life Quality Index (DLQI): a simple practical measure for routine clinical use. Clin Exp Dermatol. 1994:210-6.

21. Cardiff University Department Of Dermatology. Available form: https://www.cardiff.ac.uk/medicine/ resources/quality-of-life-questionnaires/dermatologylife-quality-index

22. Mozaffari H, Pourpak Z, Farhoodi A, Aghamohammadi A, Movahadi M, Gharaghozloo M, et al. Quality of life in atopic dermatitis patients. J Microbiol Immunol Infect. 2007;40(3):260-4.

23. Maksimović N, Janković S, Marinković J, Sekulović LK, Zivković Z, Spirić VT. Health-related quality of life in patients with atopic dermatitis. J Dermatol. 2012;39:42-7.

24. Kiebert G, Sorensen SV, Revicki D, Fagan SC, Doyle JJ, Cohen J, et al. Atopic dermatitis is associated with a decrement in health related quality of life. Int J Dermatol. 2002;41:151-8.

25. Ehlers A, Stangier U, Gieler U. Treatment of atopic dermatitis: a comparison of psychological and dermatological approaches to relapse prevention. J Consult Clin Psychol. 1995;63:624-35.

26. Jasper JPC, Span L, Molier L, Coenraads PJ. A multimodal education and treatment program for young adults with atopic dermatitis: a randomized controlled trial. Dermatol Psychosom. 2000;1:14853.

27. Gieler U, Kupfer J, Neimeier V, Brosig B, Standier U. Atopic eczema prevention programs- a new therapeutic concept for secondary prevention. Dermatol Psychosom. 2000;1:138-47.

28. Chida Y, Steptoe A, Hirakawa N, Sudo N, Kubo C. The effects of psychological intervention on atopic dermatitis. A systemic review and meta-analysis. Int Arch Allerg Immunol. 2007;144:1-9

29. Linnet J, Jemec GBE. An assessment of anxiety and dermatology life quality in patients with atopic dermatitis. Br J Dermatol. 1999;140:268-72.

30. Schmidt-Ott G, Kuensebeck HW, Jaeger B, Werfel T, Frahm K, Ruitman J, et al. Validity study of the stigmatization experience in atopic and psoriatic patients. Acta Derm Venereol. 1999;79:443-7.

31. Habib S, Morrissey S. Stress management for atopic dermatitis. Behav Change. 1999;16(4):226-36.

Cite this article as: Ranjeth R, Vijayasenan R, Amritha MS, Wesley IJ. A prospective study on impact of patient counselling on quality of life of patients with atopic dermatitis. Int J Basic Clin Pharmacol 2020;9:1860-5. 